\title{
Incorporación a la Academia de Medicina. Dr. Marcelo Wolff Reyes
}

\author{
Incorporation to the Academy of Medicine. Dr. Marcelo Wolff Reyes
}

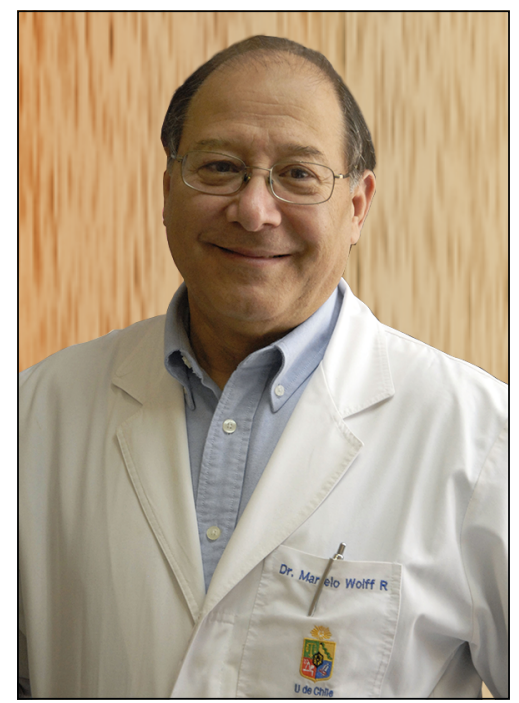

$\mathrm{C}$ uando la Academia Chilena de Medicina celebra la incorporación de un nuevo Miembro de Número, significa necesariamente que alguien ha partido y ello pudiera inspirar sentimientos encontrados. Sin embargo, pienso que hay que considerarlo como un relevo y recibir hoy a un colega como el Dr. Marcelo Wolff Reyes, es motivo de orgullo y en lo personal de gran alegría y por muchos motivos.

¿Cómo podría presentar en pocas palabras el perfil de Marcelo Wolff a nuestros colegas de la Academia y a las personas que hoy nos acompañan?

Sin duda como un destacado infectólogo, referente a nivel nacional e internacional de la infección por VIH/ SIDA, Profesor Titular de la Facultad de Medicina de la Universidad de Chile y también otros títulos y cargos.

Sin embargo, creo que el concepto que mejor lo define es ser un gran Maestro, con mayúscula. Para muchos colegas evoca la figura de los antiguos profesores de las Cátedras, grandes Maestros y mentores. Así lo reconocen sus pares y especialmente sus discípulos, que lo respetan y admiran por su disciplina de trabajo, su visión humanitaria de la medicina, su rectitud, la humildad que siempre muestra y la generosidad para compartir sus conocimientos. Todo esto acompañado de un especial sentido del humor.

Con Marcelo nuestros caminos se han encontrado en diferentes instancias a lo largo del tiempo.

Marcelo formó parte del primer grupo de estudiantes de tercer año de Medicina de la Universidad de Chile, a quienes impartí docencia en el Curso de Microbiología, cuando yo recién iniciaba mi Beca de formación académica de pediatría combinada con microbiología. En esos años, 1969, la Cátedra de Microbiología del Profesor Eduardo Dussert se impartía en el Instituto Bacteriológico, hoy Instituto de Salud Pública y tengo excelentes recuerdos de la interacción con los estudiantes de esa época, como una experiencia muy gratificante.

Pasó el tiempo y en 1983, cuando un grupo de entusiastas soñadores nos propusimos formar la Sociedad Chilena de Infectología, Marcelo se unió al grupo cuando recién regresaba de su perfeccionamiento en enfermedades infecciosas en New York. En ese tiempo, el término y el concepto de la infectología como una disciplina que incluía, desde los aspectos moleculares, patogénicos y epidemiológicos hasta los tópicos clínicos, diagnósticos y terapéuticos de la patología infecciosa, era toda una novedad para nuestro medio; costó incluso que fuera aceptada la sub especialidad por las autoridades académicas, pero pudimos sacar adelante con éxito nuestro proyecto, logrando armonizar en un ambiente de gran camaradería, respeto y amistad, la tradición con los nuevos conceptos. El primer presidente de la Sociedad Chilena de Infectología fue Mario Salcedo y Marcelo Wolff el presidente número cinco. Hoy día, esta Sociedad es una institución muy respetada y gravitante. 
Uno de los aspectos que deseo enfatizar es que Marcelo ha sido el gran formador de los infectólogos de nuestro país, creó, estableció, implementó y dirige desde su inicio, el Programa de formación en Infectología de la Escuela de Posgrado de la Facultad de Medicina de la Universidad de Chile. La Facultad de Medicina accedió a patrocinar en el año 1985, como un programa experimental, la formación de un infectólogo de adultos y en 1991 se convirtió en Programa oficial. Bajo su dirección se han formado 32 especialistas, lo cual Marcelo considera una de las cosas más gratificantes en su carrera profesional.

Pero es interesante seguir la trayectoria del Dr. Marcelo Wolff.

Nacido en Santiago, se benefició de la buena educación pública que antaño caracterizaba a nuestro país, primero en el Liceo José Victorino Lastarria y luego en el Internado Nacional Barros Arana, época que recuerda con cariño, en la que forjó grandes amistades que conserva hasta hoy. Era un ambiente agradable, mucha práctica de fútbol, algunos castigos por bromista, pero lo más estimulante fue vivir y aprender de la diversidad que encontró en el Barros Arana, donde no existían diferencias por clases sociales, apellidos o barrio de residencia. Lo más importante era ser bueno para el fútbol. Con profesores muy comprometidos y motivadores, que los estimulaban a estudiar. Recuerda especialmente a su Profesor Jefe, Fernando Cuadra, dramaturgo, a quien considera su primer mentor porque le inculcó valores como la Rectitud.

En su familia fue el primero en mostrar interés por la Medicina, desde adolescente era su aspiración. Le atraía poder ayudar a la gente y también se sintió atraído por el prestigio que significaba ser médico, lo cual piensa que hoy se ha perdido un poco.

Una vez egresado de la enseñanza media, tenía clara su vocación, decisión que tomó en forma muy independiente. Quedó seleccionado en las facultades de Medicina de la Pontificia Universidad Católica y de la Universidad de Chile; prefirió esta última. Comunicó la noticia a su madre en una solemne nota que decía "Su hijo será médico en 7 años", nota que su madre ha guardado celosamente.

En la Facultad de Medicina se sintió muy acogido desde el primer año; recuerda con especial cariño a su Profesora de Matemáticas, Clarita Misraje que utilizaba metodologías innovadoras y creativas. Posteriormente lo deslumbró el Profesor Strozzi, su maestro de histología, destacado científico y artista, ya que era un eximio dibujante.

Estudiar medicina entre los años 1967 y 1974 fue una época marcada por gran actividad política y la reforma universitaria, en la cual Marcelo participó activamente, pero sin descuidar sus estudios y sus objetivos. De esos años recuerda a su compañero Ennio Vivaldi, hoy Rector de la Casa de Bello.

Frente a la pregunta de a quién considera su mentor durante la carrera de Medicina, no duda ni un instante en asegurar que fue su esposa Irene Levy, compañera de curso desde el primer año de la carrera, quien "lo organizó y lo aterrizó", y con quien se casó cuando estaban estudiando .

Tuvieron 2 hijas, actualmente una de ellas médico psiquiatra y la otra arquitecto-urbanista. Agradece a Irene porque siempre lo ha apoyado en todas sus iniciativas y ha sido muy buena consejera. Recuerda que estudió casi toda la carrera de Medicina, en el sillón de dentista de su suegra.

Irene por su parte, confiesa que la vida junto a Marcelo siempre es impredecible, muchas ideas, muchas ventanas abiertas, muchos proyectos, intelectualmente muy activo, pero nunca aburrida y el punto de convergencia es sin duda la familia, ahora enriquecida con tres nietos.

Recién egresado de médico, obtuvo la oportunidad de trabajar en el Hospital San Borja, realizando una formación mixta en Medicina Interna y Farmacología, en un programa ad hoc bajo el auspicio del Servicio de Medicina Interna del hospital y el Departamento de Medicina Experimental del Campus Centro-Sur de la Facultad de Medicina de la Universidad de Chile. Después de 3 años de seguir este programa personalizado y de tomar contacto con el Dr. Mario Pino, microbiólogo que lo estimuló hacia la infectología, todavía en ciernes, quiso continuar su formación en Medicina Interna en el extranjero y postuló a diversos centros de Estados Unidos, siendo aceptado en New York, en el Bronx Lebanon Hospital Center, afiliado al Albert Einstein College of Medicine.

Esa experiencia fue dura al comienzo, con dificultades para comunicarse en inglés, pero al segundo año fue ascendido a Senior Resident en reconocimiento a la buena formación recibida en el Hospital San Borja. Luego de tres años, continuó su formación en Enfermedades Infecciosas en Newark, en la University of Medicine and Dentistry de New Jersey. Esta formación estuvo marcada por las patologías derivadas de la drogadicción y el SIDA. Tuvo la experiencia directa con el inicio de esta misteriosa epidemia cuando aún todavía la patología no tenía nombre.

Esta experiencia en Estados Unidos fue una escuela de la vida, la convivencia con la conjunción de múltiples culturas le enseñó la tolerancia a la diversidad y lo enriqueció culturalmente. Finalmente, Marcelo terminó hablando un fluido inglés con acento de la India. Sus mentores en esa formación fueron los profesores Donald Louria y Purnendu Sen, quienes, reconoce, lo marcaron profundamente en su pensamiento médico, con un enfoque ético y humanitario para enfrentar a sus pacientes.

Completada la especialización, llegó el momento de tomar decisiones y si bien la tentación de permanecer en Estados Unidos estuvo presente, tenía claro que su destino final estaba en Chile. A su regreso fue bien acogido en 
su hospital de origen, el San Borja, por el Dr. Guillermo Ugarte.

Marcelo tuvo rápidamente oportunidad de aplicar lo aprendido, porque en 1984 se detectaron los primeros casos de SIDA en Chile (se pensaba que nuestro país estaría ajeno a la epidemia) y eran muy pocos los médicos chilenos con experiencia en el tema. Los casos fueron aumentando y Marcelo no dudó en hacerse cargo del problema y no solamente de atender a los pacientes sino que tratar de resolver todos los problemas agregados, atención de especialistas, apoyo psicológico, atención dental, casa, comida, etc. Se hizo cargo del problema integral de estos pacientes y encontró el respaldo de las autoridades del San Borja. Recordemos que en esos tiempos tanto profesionales de la salud como familiares se resistían a atender a estos pacientes; existía un tremendo rechazo social.

Para atender todas las necesidades de los pacientes con SIDA, nace la Fundación Arriarán en un pabellón abandonado que existía en el hospital. Marcelo Wolff fue cofundador y su presidente desde 1991. Me gustaría destacar el modelo innovador de esta fundación que fue el primer centro de atención integral de enfermedad por VIH y capacitación de personal de salud, que actualmente controla alrededor de 3.500 pacientes y realiza investigación de vanguardia. ¿Cómo lo lograron? Esta Fundación es una ONG que funciona al interior de instituciones públicas, en este caso para apoyar el Servicio de Salud Metropolitano Centro Sur y el respectivo campus de la Facultad de Medicina de la Universidad de Chile, obteniendo subsidios privados y públicos que permitieron equipar las dependencias y contratar personal, para lograr los objetivos.

Demostró así una compasión positiva y práctica por sus pacientes involucrando a las instituciones. Valores éticos fundamentales que recientemente destacó en una conferencia en la Academia, la Catedrática española, Adela Cortina.

En esta ardua tarea reconoce la valiosa colaboración de su colega la Dra. Rebeca Northland, quien durante su formación en Medicina Interna conoció a Marcelo y se contagió con la Infectología; luego de formarse a su lado continuó acompañándolo hasta hoy. Han transcurrido 32 años, siguen trabajando en perfecta armonía y han construido una sólida amistad.

Sin duda que esta es una de las realizaciones que Marcelo valora como uno de sus principales logros y le ha dado muchas gratificaciones.

Además de los aspectos relevantes que hemos detallado, queremos destacar de su extenso curriculum otros aspectos de su actividad académica, que se ha desarrollado siempre en el Hospital San Borja, campus centro de la Facultad de Medicina; uno de los momentos importantes fue recibir su grado de Profesor Titular de la Universidad de Chile en 2005.

El Dr. Marcelo Wolff ha publicado más de 50 artículos en revistas nacionales, en 35 de ellos como primer autor, principalmente en Revista Médica de Chile y en Revista Chilena de Infectología; ha publicado 16 artículos en revistas internacionales, en 6 es primer autor y 5 capítulos de libros como autor o co-autor. Ha presentado los trabajos de su grupo en 24 congresos internacionales. Ha participado en 26 proyectos de investigación, siendo investigador principal en 14 de ellos.

El Dr. Wolff participa en varias sociedades: Sociedad Chilena de Infectología, de la cual fue Socio fundador y presidente, Sociedad Médica de Santiago, American College of Physicians, de la cual es Fellow, Sociedad Americana de Enfermedades Infecciosas-IDSA, de la cual es Fellow, Sociedad Panamericana de Infectología, International AIDS Society y en el Grupo de la Alianza para el Uso Prudente de los Antibióticos-APUA.

Por la labor desarrollada ha recibido el reconocimiento de sus pares y ha recibido 10 premios, algunos por trabajos presentados en congresos, Premio de Ética del Colegio Médico de Chile, Premio de Excelencia en Salud del Ministerio de Salud, Premio Excelencia Académica de la Facultad de Medicina, Premio Laureate Award 2012 del Capítulo Chileno del American College of Physicians y el First Richard and Hinda Rosenthal Award 2012 del American College of Physicians de Estados Unidos.

Ha participado como asesor temporal de OPS y OMS en varias oportunidades en el tema de SIDA y ha sido Miembro asesor del MINSAL para la elaboración de las Guías Clínicas para el tratamiento anti-retroviral en Chile.

Hoy día recibimos en la Academia como Miembro de Número a un profesional de excelencia, pero la Academia busca siempre en sus miembros algo más que marque la diferencia, así lo enfatiza siempre nuestro presidente, Dr. Rodolfo Armas. No me cabe duda que Marcelo Wolff posee con creces "ese algo más". Ha transcendido.

Me siento realmente muy honrada y emocionada de hacer esta presentación del Dr. Marcelo Wolff, estoy segura que será un gran aporte para nuestra Academia con la generosidad que lo caracteriza.

¡iMuy bien venido!!

Dra. Valeria Prado Jiménez Miembro de Número Academia Chilena de Medicina. Sillón 16.

Profesora Emérita Facultad de Medicina, Universidad de Chile 